\title{
Building a Reference Model for the PLM Processes in Engineering and Contracting Sector
}

\author{
Prof. Mario Tucci ${ }^{1}$, Ing. Romeo Bandinelli ${ }^{1}$ and Ing. Diego Carli ${ }^{2}$ \\ 1 Dipartimento di Energetica "Sergio Stecco" \\ Università degli Studi di Firenze \\ 2 Technip Italy S.p.A.
}

\begin{abstract}
The management of the processes related to proposal, design, construction, start-up, operation and decommissioning of industrial plants, in few words the whole Plant Lifecycle, are usually performed each by means of a specialised information tool, because of the peculiarities of the Engineering and Contracting $(\mathrm{E} \& \mathrm{C})$ sector. The $\mathrm{E} \& \mathrm{C}$ Companies are aware of the need to move towards an integration of such tools, under the umbrella of the PLM (Product Lifecycle Management) new acronym. As in other sectors, like the manufacturing industry, such convergence happens in two different ways: a) the modular offer of a single software vendor, usually a market leader, who tries to establish a proprietary data warehouse of all the lifecycle information; b) an agreement of different players on some standard for the representation of such information, in order to develop IT tools which are able to access and exchange meaningful information. Whichever approach will emerge as a winner, the authors think that it would be useful to define a Reference Model for the Plant Lifecycle processes, proposing an ontology for their business and technical objects, their relationships and management. Such reference model, developed in a standard modelling language, could be of great help both in developing new integrated PLM solutions, and to enable stand-alone packages to establish an effective integrations based on the data and information.
\end{abstract}

\section{Introduction}

The management of the processes related to proposal, design, construction, startup, operation and decommissioning of industrial plants, in few words the whole Plant Lifecycle, are usually performed each by means of a specialised information tool, because of the peculiarities of the Engineering and Contracting (E\&C) sector. The E\&C Companies were born in the 50' in order to answer the demand to high complexity big plants that required an effort of integration of multidisciplinary activities, fulfilling time, cost and quality needs. This way, by their nature, EPC

Please use the following format when citing this chapter:

Tucci, M., Bandinelli, R. and Carli, D., 2008, in IFIP International Federation for Information Processing, Volume 257, Lean Business Systems and Beyond, Tomasz Koch, ed.; (Boston: Springer), pp. 215-222. 
Projects are typically complex, multidisciplinary and costly, and involve a major investment by Owner Companies. As a result, the individual activities that include their design and construction work processes are themselves highly variable from project to project. Moreover, the multidisciplinary characteristics of EPC Projects force E\&C employees to use several and different tools in order to develop all the necessary documents.

The E\&C Companies are aware of the need to move towards an integration of such tools, under the umbrella of the PLM (Product Lifecycle Management) new acronym. As in other sectors, like the manufacturing industry, such convergence happens in two different ways: a) the modular offer of a single software vendor, usually a market leader, who tries to establish a proprietary data warehouse of all the lifecycle information; b) an agreement of different players on some standard for the representation of such information, in order to develop IT tools which are able to access and exchange meaningful information.

Whichever approach will emerge as a winner, the authors think that it would be useful to define a Reference Model for the Plant Lifecycle processes, proposing an ontology for their business and technical objects, their relationships and management. Such reference model, developed in a standard modeling language, could be of great help both in developing new integrated PLM solutions, and to enable stand-alone packages to establish an effective integrations based on the data and information.

\subsection{Known Results}

In literature there are many works regarding standardization of project management processes and some top down modeling of complex project at least for some part of the all process, i.e. finance and cost control [8] or product development. At the same time, several European project have tried to develop software integrations in order to manage or coordinate extended enterprises [9][10], facilitate project collaboration and provide advanced features to manage concurrent engineering.

Even if these works are correlated to $\mathrm{E} \& \mathrm{C}$ sector, in authors opinion none of them has been able to include all the features and peculiarities of this area. Moreover, even if in some projects the objective is closer to authors' vision, the methodology developed in order to achieve it is not winning.

\section{The E\&C processes}

In order to give a better comprehension of the processes to model, it's useful to briefly present the E\&C main processes as related to the first part of the Plan Lifecycle, with some forward view to the second part of it, that is the operation, maintenance and decommissioning of the plant. 


\subsection{Description of the Plant Lifecycle processes}

The Plant Lifecycle is usually divided in three main phases[1], which become four, taking into account the decommissioning of the plant.

The Front End Engineering Design involves the owner/operator $(\mathrm{O} / \mathrm{O})$ of the plant, who chooses a technology or a process, usually licensed by Technology Licensor. The latter sells the rights to use his know how and technology, usually providing a process package, that an engineering company, hired by the $\mathrm{O} / \mathrm{O}$, uses to define the basic process parameters, described in the FEED documents.

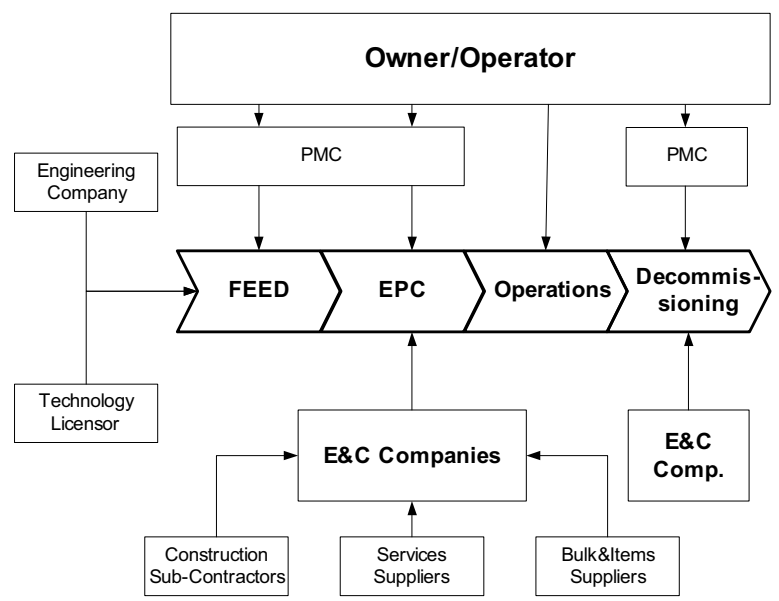

Fig. 1. The chain of participants in a Process Plant Project

Basing on the FEED documents, the O/O put out an international bid concerning the design and construction of the plant, with the help of the Project Management Consultant (PMC), who possibly implements the FEED with preliminary Piping \& Instrumentation Diagrams. The E\&C Companies, able to compete by themselves as Main Contractor or in joint venture with others, after preliminary study which leads to the bid-no bid decision, enters the Engineering, Procurement and Construction (EPC) fist phase[2], participating to the bid and, according to the rules, presenting a technical and commercial proposal with preliminary design, times, costs, subcontractors and suppliers.

The E\&C Company, winning the bid, takes the role of EPC Contractor and starts the execution phase[3]. The information flows of the Plant Lifecycle first two phases are the focus of our research which we want to manage with a new reference model.

A the end of the construction, during the commissioning activities, the EPC Contractor proves the $\mathrm{O} / \mathrm{O}$ or the $\mathrm{PMC}$ that the plant performs as stated in the contract in order to get the acceptance certificate. Usually the hand over of the plant and of all the related materials, is immediately after the final acceptance; the $\mathrm{O} / \mathrm{O}$ sometimes requires the EPC Contractor a first period of operation in order to reduce the risks of poor or unreliable plant performance. When the EPC Contractoris also 
the provider of the main critical equipments, he may be requested to operate the plant, delivering to the owner only the service (as in facilities plants), or to provide the maintenance under a Global Service Agreement.

The decommissioning of the plant, may be considered "symmetrical" to the construction and it can often be played by an E\&C Company. In special cases of chemical plants, when the decontamination of the sole is the main issue, a specialized E\&C must be involved.

\subsection{The EPC process}

In a very concise view of the EPC process (for a more detailed one see [3] and [4]), we have a Marketing and Feasibility phase leading to the Competitive Bid Participation, luckily concluded, if the bid is awarded, by the final details' negotiation and contract's signature. In this phase several documents and drawings are produced, that will be detailed and used in the next phases.

The Proposal Manager, who conducted the bid participation phase, transfers project responsibility to the Project Manager (PM), who leads the project till the hand over. We can divide such phase in five subphases, often evolving in parallel:

- Project Start-up, with the scope identification, project organisation and planning, resource definition and recruitment, coordination of the interfaces and information flow.

- Engineering, a very specific phase, involving several different competencies, technologies and design tools, and composed of Basic Design, Front-End, Item and Bulk Engineering, Construction Engineering and Field Engineering.

- Procurement, in which it is important to order in advance the critical equipments from selected and qualified vendors, and to find the local providers for bulk materials. The purchase activities are followed by the material management which consists in expediting vendors' work, carrying out periodical inspection and organizing shipment on the site..

- Construction, which comprises the Planning of construction activities and their execution, possibly under the responsibility of a Construction Manager, and using local civil and mechanical subcontractors.

- Close-out, with the Precommissioning, Commisioning/Start-up, and the issue of the Provisional and Final Acceptance Certificate.

\subsection{Why EPC projects is not only Project Management.}

Even if Project Management (PM) activities, and consequently, PM techniques and software tools, are the core of the EPC process, there are several reasons to have a broader view of this subject, which we try to list hereafter:

a. PM is just the glue of a lot of different technical activities ranging from materials management, from cost to progress control, from quality to risk management, from integration and coordination actions to problem solving techniques.

b. EPC process is just one phase, even if very important, in the plant lifecycle, and, as the Product Lifecycle Management (PLM) paradigm teaches, it's 
worthwhile, that is more effective and efficient, to manage all the lifecycle of the product, from the idea to the use and decommissioning, with integrated software tools, based on common model for the representation of the product (in our instance the plant) and all the processes to design, produce, operate, maintain and dismiss it.

c. Even if PLM could be the right paradigm and we could imagine to utilizing PLM software suites and tools, the structure of E\&C market is quite different from the manufacturing industry, where the PLM was developed. One of the reasons is the relationship among the players, as showed in Figure 1, where the strong player is the $\mathrm{O} / \mathrm{O}$, who often drives the $\mathrm{E} \& \mathrm{C}$ adoption of software standards, as the final delivery of a digital model of the plant is usually considered part of the scope of work. The $\mathrm{O} / \mathrm{O}$ actually uses such digital model in his software tools for maintenance management and related tasks, as revamping and decommissioning.

d. PM tools usually integrated in ERP solutions are considered incapable of managing a complex EPC project, whilst the specialized PM packages normally used by E\&C companies are provided by vendors who don't have the power to impose their PM centric view to the vendors of the other tools used in EPC projects.

A review of the IT systems' architectures used by main Italian E\&C Companies [6] showed the great number of different software packages used in the EPC process, and the variety of solutions adopted. These software families can be classified as Electronic Document Management Systems, Project Management, Computer Aided Design/Engineering, Plat Data Warehouse, Material Management Systems, ERP, eProcurement Systems, Construction Management Systems.

In many cases more than a dozen of packages are used, each for a different aspect or phase of the EPC process (see Fig. 2), never covering all the activities, and such tools are rarely integrated. Even when integration exists, it's more common that exportation files are generated, converted and adapted to the data model of the destination package, and finally imported into it.

This solution creates several problems, as opposed to actual data centered integration:

a. The creation of conversion software to interface each package to all the others with which it has to establish and information flow.

b. The upgrading of these interfaces, every time a new major release of software packages is delivered.

c. The frequent generation of export files, and their importation in the destination package, possibly loosing the changes made in this last one.

d. Being this task heavy and error prone, the consequence is a poor real time updating of the information .

e. If a software vendor, as strong as the CAD producers in this sector, tries to provide the interfaces to the main software packages out of his scope, he has to develop and maintain a plethora of modules or functionality, leading to a costly and low effective solution. 


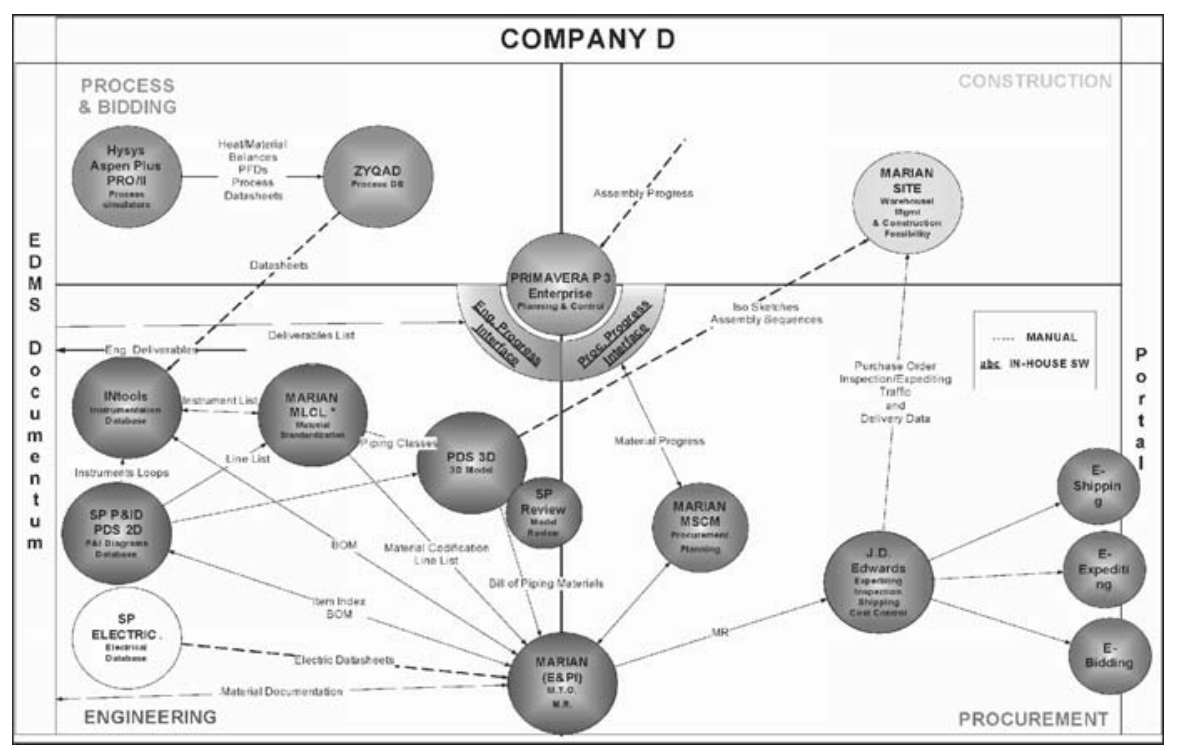

Fig. 2. One of the IT systems' architecture mapped in [6]

\section{Our proposal}

As a matter of fact, the coexistence and the use of several software and tools is a necessity of E\&C companies. Therefore, the development of an integrated software cannot be the only way to solve the above problems. Authors' idea is to develop a Reference Model for the Plant Lifecycle processes, starting from EPC process, proposing an ontology for their business and technical objects, their relationships and management.

The use of this reference model will permit to define a standard for the exchange of the information and for object coding, that could be used by all the commercial tools, in order to guarantee the interoperability among the software, and the exchange of information across different documents.

The Italian E\&C Companies are attempting to develop highly integrated systems for the engineering area, using tools with data-centric structure. This means bringing together the information required by several users in centralized databases for every design tool. In addition, the aim is to make the information contained in the individual databases accessible, thanks to a Plant Data Warehouse (PDW). A PDW makes it possible to move from one application to another, while maintaining a good quality of the information.

Even if some software houses are working is this direction, together with their customers, no important results have been achieved so far. Author's opinion is that, in order to solve this impasse, a creation of a consortium of several software houses and $\mathrm{E} \& \mathrm{C}$ companies is necessary to define and approve a reference model, and consequently a standard for EPC processes, data and documents.

In order to achieve this long view result, some first step has been carried out by the authors. 
At the beginning[7], the EPC phases were analyzed and modeled. Then the use of UML as a formalism permitted to describe processes in an object oriented view, focusing on the exchange of information among documents along the whole project life.

Starting from this vision, several diagrams describing the phases of an EPC project were drawn. First the user cases diagrams were developed, then all the packages diagrams were described, splitting them into: roles, elements, phases and documents. Then timing diagrams were drawn, dividing them into sequential and state diagrams.

Hereafter a part of the document diagram is reported in order to demonstrate the approach.

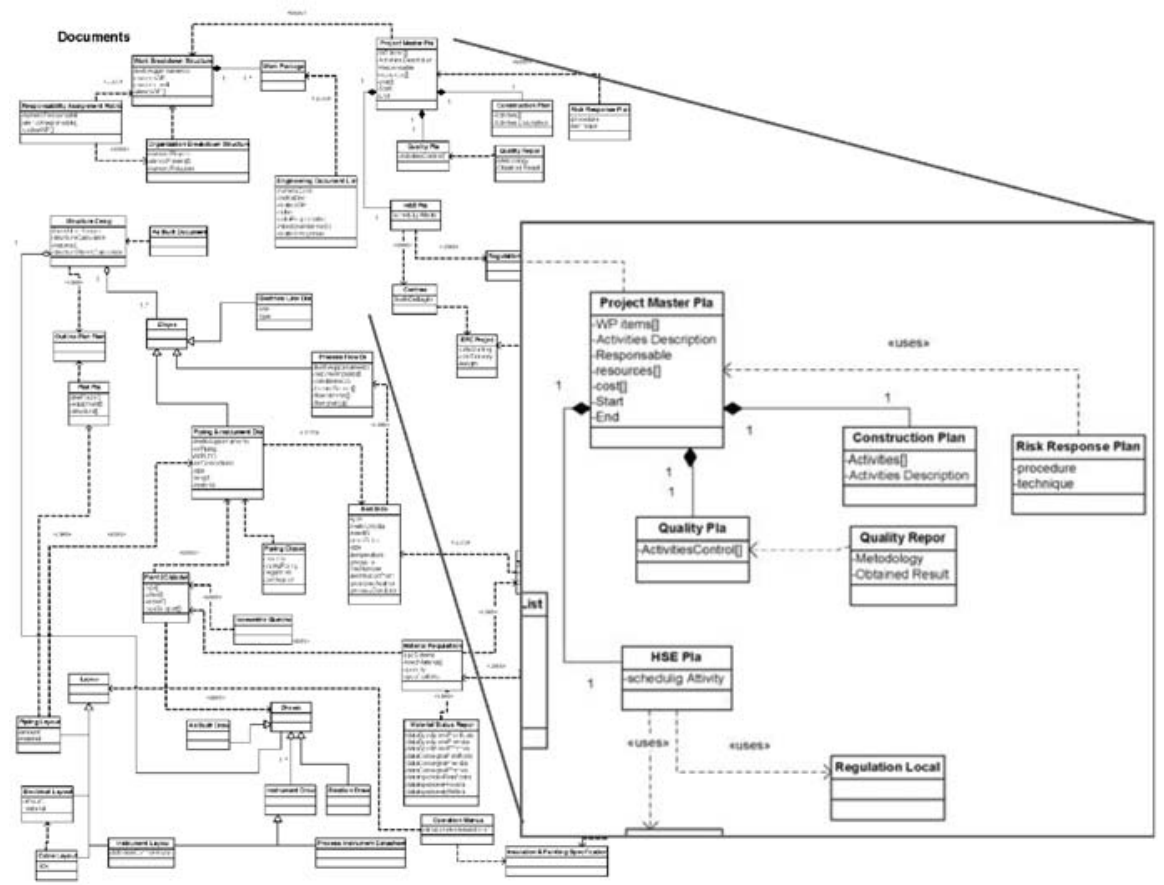

Fig. 3. The document diagram

At the moment a validation phase is ongoing, checking the applicability of such reference model to Italian $\mathrm{E} \& \mathrm{C}$ companies and the first results are positive, as the modeling started from the review in [6]. Obviously we do not expect a perfect match of our reference model to the way the single company works, or even to the single project manager inside the same company. But such diversity is often due to the habits of a PM and it is not justified but actual needs. The sharing of a common reference model is always an opportunity to reengineering the processes to converge to the best practices. This standardisation of practices is a problem recognised by the companies who are not able to force their PMs, as a formalised approach supported 
by software tools is still missing. The companies could benefit by our proposal in this area as well

In parallel the reference model is being submitted to the review of a main software vendors of this sector.

If the first two phases will have positive outcomes, the next step should be the creation of a consortium among the above actors, in order to develop a complete reference model. With such standard the software vendors would be able to develop compliant software tools, both starting from scratch or creating interface models only to this objects.

\section{Acknowledgments}

The authors thank Marialetizia Arcuri for her broad and deep contribution to the developmet of the reference model so far under the supervision of our colleagues Prof. Paolo Nesi and Ph.D student Tommaso Martini .

\section{References}

1. Middlemas D., "Integrated Project Execution", Aveva White Paper, www.aveva.com, 2003.

2. Caron F., Corso A., Guarella F. et al., "Project Management in Progress", Franco Angeli Editore, Milano, 1997.

3. Titolo M., La competizione internazionale nel mondo dell'impiantistica, Franco Angeli Editore, Milano, 2005.

4. Tucci M., Carli D., Sistemi informativi nei processi delle società di E\&C, Impiantistica Italiana, Maggio/Giugno 2006.

5. Tucci M., Carli D., The PLM Business Model in the Engineering and Contracting Companies, Proceedings of the PLM06, International Conference on Product Lifecycle Management, Bangalore, India, 2006, July 10th- $12^{\text {th }}$.

6. Carli D., Information technology supporting the process of Italian E\&C Companies, Master Thesis, Mechanical Engineering, Università degli Studi di Firenze, 2005.

7. Arcuri M., Modello di riferimento per le fasi di gestione dei progetti di una società di Engineering \& Contracting, Master Thesis, Informatic Engineering, Università degli Studi di Firenze, 2005.

8. Mosca R., Revetria R., and Forgia C., Top Down Modeling and Monte Carlo Simulation for Financial \& Cost Control in Complex Projects, Proceeding of Modelling, Identification, and Control, 2005.

9. Whales project, website: http://whales.gformula.com/, last access June 2006.

10. Ecolead project, website: http://virtual.vtt.fi/virtual/ecolead/, last access June 2006. 